\title{
Os Conselhos Municipais de Educação no Brasil: um balanço das referências nacionais (1996-2002)*
}

\author{
Donaldo Bello de Souza \\ Maria Celi Chaves Vasconcelos
}

\section{Resumo}

presente trabalho efetivou-se com base em um expressivo recorte da produção científica brasileira em torno do eixo temático Política, Gestão e Financiamento de Sistemas Municipais Públicos de Educação no Brasil, cobrindo o período 1996 2002, o que resultou no resumo de 355 referências publicadas no País, correspondentes à produção de cerca de 266 autores. Da análise desse eixo temático, emergiram, entre outras questões, dados que permitiram elaborar um breve balanço sobre a produção teórico-conceitual e teórico-empírica que versa sobre os Conselhos na área de Educação no Brasil, circunscrita àquele período, enfocando-se, especialmente, as referências que tomam por objeto central ou secundário, os Conselhos Municipais de Educação (CMEs) e os Conselhos de Acompanhamento e Controle Social
(CACSs), levando-se em consideração três segmentos deste último tipo de Conselho: do FUNDEF, do PNAE e do Programa Nacional Bolsa (atual Bolsa Família). A título de resumo de seus principais resultados, cabe, inicialmente, destacar o fato de que não se notou a presença de estudos voltados para estes dois últimos Programas Federais, havendo, em exclusivo, uma baixa concentração de trabalhos na esfera unicamente dos Conselhos do FUNDEF. Preponderam referências individuais, cuja produção científica, majoritariamente, é originária da Região Sudeste do País, sendo recorrente a preocupação sobre a problemática da participação da sociedade local nos Conselhos. Por fim, postula-se que urge a necessidade de se melhor compreender a natureza e o

\footnotetext{
"Trabalho apresentado no XIV Colóquio de la Association Francophone Internationale de Recherche Scientifique en Education (AFIRSE/AIPELF), realizado na Faculdade de Psicologia e de Ciência da Educação da Universidade de Lisboa, Portugal, de 16 a 18 fevereiro de 2006, cuja temática central se constituiu no "Balanço da Investigação em Educação de 1960 a 2005 , no âmbito do campo de estudos em Política e Administração da Educação".
} 
funcionamento desses Conselhos, tornandoos objetos de um universo quantitativa e qualitativamente mais amplo de investigações, visando, sobretudo, à intervenção social.

Palavras-chave: Conselhos Municipais de Educação. Conselhos de acompanhamento e controle social. Participação da sociedade civil. Descentralização. Municipalização da educação.

\section{Abstract}

\section{The Municipal Councils of Education in Brazil: a balance of national references (1996 - 2002)}

The present task was done based on an expressive draft of the scientific Brazilian production about the theme Politics, Administration and Finance of the Municipal Public Systems of Education in Brazil, between 19962002 which resulted in a summary of 355 published references in the country, corresponding to the production of about 266 authors. From this theme analysis, emerged, between other questions, data that permitted a brief balance about the theoric conceptual and theoric - empirical production that verse on the councils of the education area in Brazil, referring to that period, focusing, specially, on the references that take as a central object or a secondary one of the Municipal Council of Education (CMEs) and the Council of Accompamiment and Social Control (CACSs) considering three segments from this last type of council: from FUNDEF, from PNAE and from the actual Scholarship Family Program. As a summary of its main results, unitially, it can be showed the fact that no studies were turned to the last two Federal programs, having exclusively, a low concentration of work in FUNDEF. Individual references reign, whose scientific production, mainly, is originally from the Southeru Region, being appealing the worries about the problem of the participation of the local society on councils. Finally, it's na urge for the necessity to understand better the nature and functioning of these councils, turning the objects from a wider quantitative and qualitative universe, focusing, above all, the social intervention. Keywords: Municipal Councils of Education. Councils of accompaniment and social control. Participation of the civil society. Decentralization and municipalization of education.

\section{Resumen}

\section{Los Consejos Municipales de Educación en Brasil: un análisis de las referencias nacionales (1996-2002)}

El presente trabajo se realizó con base en un expresivo recorte de la producción científica brasileña, en torno del eje temático Política, Gestión y Financiamiento de Sistemas Municipales Públicos de Educación en Brasil, cubriendo el período 1996-2002, lo que resultó en el resumen de 355 referencias publicadas en el país, correspondientes a la producción de alrededor de 266 autores. Del análisis de este eje 
temático, emergieron, entre otras cuestiones, datos que permitieron elaborar un breve análisis sobre la producción teórica-conceptual y teóricaempírica que trata sobre los Consejos, en el área de Educación en Brasil, circunscripta a aquel período, enfocándose, especialmente, las referencias que toman por objeto central o secundario, los Consejos Municipales de Educación (CMEs) y los Consejos de Acompañamiento y Control Social (CACSs), llevándose en consideración tres segmentos de este último tipo de Consejo: del FUNDEF, del PNAE, y del Programa Nacional de Becas (actual Beca Familia). A título de resumen de sus principales resultados, cabe, inicialmente, destacar el hecho de que no se notó la presencia de estudios dirigidos para estos últimos Programas Federales, habiendo, en exclusivo, una baja concentración de trabajos en la esfera únicamente de los Consejos del FUNDEF. Prevalecen referencias individuales, cuya producción científica, en su mayoría, es oriunda de la Región Sudeste del país, siendo recurrente la preocupación sobre la problemática de la sociedad local en los Consejos. Por fin, se postula que urge la necesidad de comprenderse mejor la naturaleza y el funcionamiento de esos Consejos, volviéndolos objetos de un universo cuantitativamente $y$ cualitativamente más amplio de investigaciones, teniendo como objetivo, sobre todo, la intervención social.

Palabras clave: Consejos Municipales de Educación. Consejos de acompañamiento y control social. Participación de la sociedad civil. Descentralización y municipalización de la educación.

\section{Introdução}

No presente trabalho, intenta-se examinar uma parte expressiva da produção científica brasileira sobe os Conselhos Municipais de Educação (CMEs) e sobre os Conselhos Municipais de Acompanhamento e Controle Social (CACSs), cobrindo o período de publicação, em âmbito nacional, de 1996 a 2002. Trata-se de resultados de um dos produtos da pesquisa de Souza e Faria (2002), denominada "Mapa Estadual das Reformas Educacionais Pós-LDB 9.394/96: leituras, posicionamentos e ações das Secretarias Municipais de Educação do Estado do Rio de Janeiro (2001-2004)", realizada pelo Núcleo de Estudos em Políticas de Educação (NUEPE), da Faculdade de Educação da Universidade do Estado do Rio de Janeiro (UERJ), ao longo dos anos 2002-2005'.

O levantamento em questão, balizado em torno do eixo temático "Política, Gestão e Financiamento de Sistemas Municipais Públicos de Educação no Brasil", se valeu de meios eletrônicos, com prevalên-

\footnotetext{
${ }^{1}$ Em suas várias fases de execução, a pesquisa beneficiou-se de importantes apoios provenientes tanto da UERJ - em termos da concessão de Bolsa de Pesquisa para dedicação exclusiva à investigação, dirigida ao seu coordenador, Prof. Donaldo Bello de Souza, efetivada pela via do Programa Prociencia da Sub-reitoria de Pós-Graduação e Pesquisa (SR-2) -, quanto das agências de fomento à pesquisa: Fundação Carlos Chagas Filho - Amparo à Pesquisa do Estado do Rio de Janeiro (FAPERJ) e do Conselho Nacional de Desenvolvimento Científico e Tecnológico (CNPq), além do apoio da União Nacional dos Dirigentes Municipais de Educação (UNDIME-RJ). Em seu cômputo geral, a pesquisa visou o conhecimento acerca do conjunto das políticas em desenvolvimento pelas Secretarias Municipais de Educação (SMEs) do Estado, no período de gestão 2001-2004, de modo a poderse inferir sobre as dificuldades enfrentadas pelas prefeituras fluminenses face ao processo de descentralização do ensino via municipalização. De um lado, procurou contemplar aspectos relativos à Gestão e ao Financiamento da Educação (1 1 indicadores de sondagem) e, de outro, concernentes à especificidade dos Níveis \& Modalidades de Ensino (9 indicadores de sondagem) possivelmente praticados pela rede publica dessas localidades.
} 
cia de consulta a diversas bases bibliográficas acessadas via Internet ou residentes em CD-ROMs, como, propriamente, dos acervos físicos concernentes a nove bibliotecas localizadas no Município do Rio de Janeiro (SOUZA; FARIA, 2005).

Embora, desde a sua origem, o estudo tenha perseguido a exaustividade, quer em relação aos quatro tipos de fontes bibliográficas em que se assentou, quer em termos do recorte temporal adotado, seu resultado final não pode ser considerado efetivamente definitivo, uma vez que, em determinados casos, não se logrou esgotar o exame do que possivelmente tenha sido publicado.

Enquanto a pesquisa pautada em "Livros e em partes de livros", assim como em "Periódicos", pode ser considerada de relativa exaustividade, os "Trabalhos em Anais de eventos científicos" não vieram a ser ponderados em sua totalidade - a exceção daqueles publicados nos Anais da Associação Nacional de Pós-Graduação e Pesquisa em Educação (ANPEd) e da Conferência Nacional de Educação, Cultura e Desporto (levada a efeito, em 2001, pela Câmara dos
Deputados), assim como as "Teses e dissertações" que, até a data de encerramento do levantamento (dezembro de 2003), o Banco de Teses da Fundação Coordenação de Aperfeiçoamento de Pessoal de Nível Superior (CAPES), ainda não havia disponibilizado os resumos dos trabalhos defendidos no ano de 2002, o que impôs a delimitação da análise deste tipo de fonte, em extraordinário, ao período 1996-2001.

Do total de 355 referências selecionadas, preponderam 114 "artigos em periódicos" $(32,1 \%)^{2}$ e 113 "livros no todo e partes de livros" $(31,8 \%)^{3}$, seguidos de 88 "dissertações e teses" $(24,8 \%)^{4}$ e, com menor freqüência de ocorrência, de 40 "trabalhos em anais de eventos científicos" $(11,3 \%)^{5}$, todos realizados no País. Desse conjunto, 98 referências $(27,6 \%)$ correspondem à categoria temática "Gestão de Sistemas Municipais Públicos de Educação", enquanto que os $72,4 \%$ restantes remetem as outras três categorias operadas pelo levantamento, a saber: Educação Municipal Pública e Legislação (13\%), Financiamento da Educação Municipal Pública (31\%) e Políticas Públicas para a Educação Municipal $(28,4 \%)$ (SOUZA; FARIA, 2005).

\footnotetext{
2 Dos 94 periódicos consultados, 69 pertencem à área de educação $(73,4 \%)$, enquanto $25(26,6 \%)$ a outros campos do conhecimento ponderados: Administração, Ciências Sociais e Política e, ainda, revistas científicas de natureza multidisciplinar.

3 De modo geral, logrou-se acessar na Internet a página de 76 editoras, assim subdivididas: 36 particulares, 20 de Universidades Federais, 7 de Universidades Estaduais, 8 de Universidades Confessionais, 2 de Universidades Particulares e 3 de Fundações, além da consulta direta às bases de dados das bibliotecas virtuais e físicas visitadas.

${ }^{4}$ Deste total de 88 referências, 72,7\% correspondem a Dissertações de Mestrado e 27\% a Teses de Doutorado, com prevalência de estudos na área de educação (média de 82,3\%), em que pese, também, a identificação e consideração de outros trabalhos $(17,7 \%)$ realizados nos seguintes campos: Administração, Ciência Política, Ciências Contábeis, Ciências Sociais, Economia, Saúde Coletiva, Serviço Social e, ainda, Transportes.

${ }^{5}$ Em face do elevado quantitativo de entidades promotoras de eventos científicos no País, constituídas por associações, instituições de ensino superior, organismos governamentais, entre outros - em certa medida dispersos entre as várias Regiões e Estados -, e, ainda, em decorrência dos múltiplos formatos que assumem - Seminários, Simpósios, Reuniões, Encontros, Congressos, Jornadas, Fóruns, etc. - , restringiu-se, sobremaneira, o escopo das referências que viriam a servir ao exame dos Trabalhos em Anais de Eventos Científicos. Delimitou-se, portanto, aos eventos organizados pela Associação Nacional de Pós-graduação em Educação (ANPEd), pela Associação Nacional de Pós-graduação em Ciências Sociais (ANPOCS) e, ainda, pela Associação Nacional de Política e Administração da Educação (ANPAE), isto em função da tradição e reputação científico-acadêmica dos encontros que promovem e, sobretudo, pertinência das atividades desenvolvidas por alguns de seus Grupos de Trabalho (GTs) em relação ao eixo temático deste estudo. Além destas entidades, levou-se igualmente em conta iniciativa da Comissão de Educação, Cultura e Desporto da Câmara dos Deputados em torno da realização de evento na área de educação.
} 
Dentre o montante de referências categorizadas como vinculadas à temática "Gestão de Sistemas Municipais Públicos de Educação", identificaram-se 34 estudos $(34,7 \%$ do conjunto total de publicações relativas a essa categoria) com foco nos Conselhos Municipais, assim distribuídos: 21 referências sobre os CMEs (62\%) e 13 versando sobre os CACSs (38\%), conforme mais adiante detalhado ${ }^{6}$.

Do ponto de vista da estrutura do presente artigo, a seguir, busca-se resumidamente traçar um panorama acerca do contexto histórico e social no qual os Conselhos de Educação são constituídos no Brasil, na década de 1990, para, a partir de então, estabelecer-se algumas deferências a respeito da produção científica publicada no País sobre os CMEs e os CACSs, visando, no final do artigo, a postular algumas conclusões e recomendações.

\section{A Criação dos Conselhos na área de educação no Brasil}

Retrospectivamente, é possível afirmar que a organização da educação nacional, a partir Constituição Federal (CF) de 1934, foi estabelecida de forma sistêmica, através de "sistemas educacionais", que correspondiam a três esferas do Poder Público: Federal, do Distrito Federal e Estadual. Mais tarde, a Constituição de 1946 veio a prever a concepção de uma lei para disciplinar a educação no País, estabelecendo as competências e incumbências de cada um dos sistemas educacionais existentes.
Nessa perspectiva, foi encaminhado ao Congresso Nacional o projeto da primeira Lei de Diretrizes e Bases da Educação (LDB) no País que, sem conseguir atender aos interesses dos diferentes setores dominantes naquele momento histórico, permaneceu durante 15 anos em "discussão", sendo, finalmente, sancionada em 1961. Conhecida como a Lei 4024/61, suas disposições vigoraram até que sucessivas reformas, realizadas entre as décadas de 1960 e 1970, alteraram a formatação do ensino desde a educação básica até o ensino superior.

A CF de 1988, em vigor, veio suscitar algumas importantes mudanças na legislação educacional, comungando com as demandas sociais existentes na época, que afirmavam a necessidade de normas mais adequadas às transformações ocorridas no País nos anos 1980 - em que pesem as tensões político-sociais e partidárias que se faziam presentes desde a Constituinte. Apesar das demandas sociais existentes, a regulamentação dos dispositivos constitucionais de 1988 só foi realizada em 1996, por intermédio da promulgação da "nova" LDBEN, Lei 9.394/96 (BRASIL, 1996), cujo texto não apenas ratifica a organização sistêmica, já praticada, como normatiza a condição de sistemas "autônomos" atribuída aos Municípios pela CF 1988. Assim, a organização sistêmica anterior que estava prevista no âmbito das três esferas de governo (Federal, do Distrito Federal e Estadual), passa a ser composta, agora, por quatro, caracterizando sistemas autônomos e com incumbências e prioridades diferenciadas: o sistema Federal de ensino; o sistema de ensino do Distrito Federal; o sistema de ensino dos Es-

\footnotetext{
${ }^{6}$ Neste estudo, além das referências em questão, foram consideradas algumas outras obras publicadas em período posterior ao do levantamento original, resultante de uma atualização agora em processo de elaboração, enfocando o período $2003-2005$.
} 
tados e o sistema de ensino dos Municípios, garantidos, pelo menos no âmbito legal, o Regime de Colaboração entre eles. Com o estabelecimento do sistema de ensino dos Municípios, previsto na CF de 1988, e regulamentado na Lei 9.394/96, há uma reestruturação na organização da educação nacional, considerando as incumbências delegadas a estes e a necessidade de financiamento do Governo Federal, para que tais medidas fossem postas em prática.

Dessa forma, os sistemas municipais de ensino deveriam constituir-se como organizações independentes e autônomas, cujas regulamentações e normas seriam previstas por seus próprios órgãos normativos, os Conselhos de Educação, que considerariam, entretanto, em suas deliberações, o disposto na LDBEN, no Plano Nacional de Educação (PNE) e nas Diretrizes Nacionais emanadas do Conselho Nacional de Educação (CNE). Isto é, a autonomia anunciada a Estados e Municípios poderia tornar-se realidade, desde que não descumprisse a lei e as normas estabelecidas em âmbito federal ${ }^{7}$.

Conforme pode ser observado, tais mudanças ocorrem a partir da segunda metade dos anos 1980, exatamente quando a redemocratização do País irá favorecer a recuperação das bases do Estado federativo brasileiro (eleições diretas e descentralização fiscal), com forte impacto sobre o processo de descentralização das políticas sociais (ARRETCHE, 1999) que, ao longo dos idos de 1990, virá a ser traduzido, em termos práticos, em processos de desconcentração financeira e executiva pautados na manuten- ção da centralização normativa e política (MONTAÑO, 2003), em meio à imbricação das crises do Estado, da administração pública, da federação e, ainda, da representação política (NOGUEIRA, 1997)

No campo social, as políticas implantadas estariam ainda marcadas por recomendações advindas de diversos fóruns mundiais e regionais, como, por exemplo, decorrentes dos compromissos firmados pelo Brasil na chamada Declaração de Jomtien (Tailândia, 1990), voltados para a universalização do acesso à educação e para a promoção da eqüidade (NOGUEIRA, 2001), assim como, para a definição de competências e responsabilidades das instâncias de governo em relação à gestão e ao financiamento da Educação Básica (ABICALIL, 2001; FREITAS, 1998).

As políticas governamentais passam, então, a adotar o caminho da racionalidade financeira, implicando redução dos gastos públicos e do tamanho do Estado, assim como a abertura do País ao capital financeiro internacional. A partir disto, o uso instrumental do conceito de descentralização passa a ser, majoritariamente, aplicado como desconcentração, expressando a estratégia de retirada do Estado da prestação de serviços públicos essenciais à sociedade, com profundos reflexos na área de educação, entre outras (ABREU, 1999; SAVIANI, 1999, ARELARO, 1999). Irá, portanto, repercutir em um maior envolvimento direto do Município na captação de suas próprias demandas, no controle de gastos e na inspeção do cumprimento das

\footnotetext{
${ }^{7}$ Assim como aos sistemas de ensino é apontada autonomia na gestão de sua rede de instituições de ensino tanto pública, bem como a normatização dos níveis de educação privada, os mesmos deveriam, também, assegurar às unidades escolares de Educação Básica pertencentes ao seu sistema, progressivos graus de autonomia pedagógica, administrativa e de gestão financeira, a partir da proposta pedagógica estabelecida.
} 
metas federais e/ou estaduais estabelecidas, agora não unicamente pelo poder público local mas, também, pela via da responsabilização da sociedade civil (MENEZES, 2001).

Contudo, não se deve perder de vista que os mecanismos de participação que, a partir daí serão criados, voltados à participação da sociedade civil na gestão local, decorrem, a um só tempo, da influência de diversos movimentos democrático-populares iniciados ao longo das décadas de 1960 e 1970, manifestos em várias frentes de lutas sociais (CALDERÓN; MARIM, 2002), e também constituídos a partir de experiências remanescentes de alguns outros movimentos sociais dos anos 1980 (GOHN, 1998, 2001), que lograram êxito em estabelecer pressões em prol de ideais democráticos e de institucionalização de canais de participação popular na gestão pública, especialmente, em meio aos debates da Assembléia Nacional Constituinte.nos idos de 1990, observase, portanto, a estruturação de novas redes associativas, dentre as quais a criação de Conselhos nas diversas áreas das políticas públicas do País, amparados por ampla base legal, assumindo diversos formatos e funções, sendo caracteristicamente compostos por representantes do poder público e, conforme já assinalado, da sociedade civil, a exemplo das iniciativas em torno da criação dos Conselhos de Direitos, de Assistência Social, de Saúde, de Educação, etc. Neste último caso, disseminam-se os Conselhos Escolares, os Conselhos de Classe e de Série, os Grêmios Estudantis, os Conselhos Municipais de Educação - CMEs, e Conselhos de Acompanhamento e Controle Social - CACSs, estas duas últimas instâncias, tomadas como objeto central de estudo.

\section{A produção científica sobre os CMEs}

Dos 21 estudos analisados, o maior número de produções científicas relativas aos CMEs em tela concentra-se na Região Sudeste, especialmente, no Estado de São Paulo, reproduzindo as tendências observadas no cômputo geral do levantamento bibliográfico realizado. Dos 9 trabalhos analisados relativos a este Estado, grande parte remete às discussões em torno da descentralização e da municipalização da educação e, os demais enfocam os meios criados para a participação efetiva da comunidade junto ao sistema de ensino. Nesse último caso, encontram-se as pesquisas descritas em Bravo (2001), que analisa a relação entre educação e sociedade no município de Indaiatuba (SP), constatando que o CME deste Município vem propondo ações conjuntas de conscientização e discussão de políticas educacionais, voltadas para programas governamentais federais de apoio; e Calderón e Marin (2002), que, na mesma perspectiva, analisam o funcionamento dos CMEs, destacando o processo histórico da criação das bases legais para a sua implantação, apontando como referência de participação popular, nos anos 80, o CME de São Paulo sob a gestão do Secretário Paulo Freire. Aborda, ainda, resultados de pesquisa relativa ao estudo dos CMEs na Região do Brejo do Estado da $P B$, envolvendo 11 Municípios (não informados pelo autor), e o caso do CME de Santo André (SP). $\bigcirc$ autor conclui, ressaltando a importância da participação popular na gestão pública, embora considere haver ainda muitas dificuldades para a viabilização dos Conselhos Municipais, considerados como mecanismos efetivamente democratizantes. Tal aspecto é igualmente 
apontado por Carvalho et al. (2001), com base no estudo de 4 Municípios da microrregião de Campinas (SP) - Americana, Campinas, Paulínia e Valinhos -, que constatam a ausência de uma política articulada à construção de espaços de discussão, fato atribuído à uma possível fragilidade do trabalho desses Conselhos.

Com ênfase na descentralização, Lima e Viriato (2000) discutem as políticas educacionais de participação e autonomia dos Estados de São Paulo e Paraná (a partir da década de 1980), partindo do pressuposto de que essas políticas concebem a descentralização como, de fato, desconcentradora das obrigações sociais do Estado, condicionando o processo de desestatização da educação pública na década de 1990.

No que se refere à municipalização da educação como temática principal abordada, Oliveira e Teixeira (2001), em estudo voltado para a análise de cerca de 60 resumos de pesquisas referentes à categoria "Municipalização e Gestão Municipal" (1991-1997), identificam que, apesar de haver uma grande preponderância de trabalhos concernentes à municipalização do ensino, a ênfase encontra-se, majoritariamente, posta em estudos que tomam por alvo trabalhos avaliativos de projetos / programas para a Municipalização, fazendo com que as análises sobre os Conselhos subsumam em face dessa temática, assumindo, portanto, caráter não central, ou seja, secundário. Nessa linha de investigação, Oliveira e Ganzeli (2001), apoiados em pesquisa realizada no Município de $\mathrm{Pi}$ racicaba (SP), apontam, entre outros aspectos, o CME e as decorrências do processo de municipalização. Aprofundando o assunto, destaca-se também Borges
(2000), que discute o processo de municipalização da educação no Estado de São Paulo, com foco nos Municípios de MogiGuaçu, Mogi-Mirim e Presidente Prudente e as pressões realizadas pela Secretaria de Estado de Educação sobre esses Municípios, levando-os a optar pela municipalização da totalidade das matrículas nas séries iniciais do Ensino Fundamental, já no início de 1998. Por outro lado, Natera (2001) analisa o processo de elaboração dos documentos que viabilizaram a municipalização do ensino no Município de Saltinho (SP) e as leis municipais que institucionalizaram o $\mathrm{CME}$, tendo como propósito principal verificar se estes, em termos reais, se constituem em instrumento de democratização da gestão do sistema municipal de ensino, principalmente, no que diz respeito à participação dos professores.

Partindo para uma análise de cunho teórico-conceitual, o estudo realizado por Vilaboim (1998) discute a omissão no texto da Lei 9.394/96 (BRASIL, 1996) sobre os CEEs, resgatando o papel histórico dos mesmos, a partir da CF (1934). Afirma que os Estados não devem abrir mão de seus Conselhos de Educação, entendidos como soberanos nas decisões que thes competem, afirmando que a Lei 9.394/96, por não ter especificado a função normativa dos CEEs e dos CMEs, acabou por abrir espaço para que os sistemas de ensino prescindissem desses colegiados e viessem a eleger um outro, com laços mais estreitos em relação às suas Secretarias de Educação, para exercer a função legislativa, quando, historicamente, esteve marcado pela função executiva. Da mesma forma, Silva (2001) identifica o estilo de administração dos Secretários Municipais de Educação, tomando por base de análise os preceitos 
teóricos que servem à consubstancialização da administração de tendência conservadora e de tendência progressista, enfocando os Municípios de Santa Cruz da Conceição, Leme e Limeira, no Estado de SP. Conclui que o estilo de administração dos secretários entrevistados é de tendência conservadora, no sentido de que foi observada a ausência de incentivos dos mesmos a uma efetiva participação de professores, diretores e pais engajados nos rumos da educação no Município e destaca, mesmo, a ausência do CME e de processos de descentralização / municipalização ${ }^{8}$.

Os estudos investigados que tomam como objeto os CMEs na região Nordeste, concentram sua atenção no Estado da Bahia e, das 5 publicações revisadas, 4 pertencem ao mesmo autor (MEIRA, 1998, 2000, 2001, 2004), que analisa a importância do CME para a descentralização da gestão educacional, com base em nove Municípios do Estado da BA (Salvador, Simões Filho, Vitória da Conquista, Catu, Parapiranga, Guanambi, Camaçari, Feira de Santana, Serrinha), sendo que sete deles já possuíam delegação de competência do CEE-BA. O autor aprofunda seus estudos, ressaltando nas últimas 3 publicações, que o CME ainda não pode ser considerado como fundamental na melhoria da qualidade educacional oferecida pelas localidades, entre outras razões por que, em muitos Municípios, apesar de sua presença institucional, não cumpre com as suas atribuições, em virtude do desconhecimento, por parte dos conselheiros, não só das suas próprias funções, como daquelas do citado órgão. Ainda referente ao Estado da Bahia, Rocha (2001) demonstra que, do ponto de vista jurídico-político, a norma constitucional e a recente legisla- ção educacional brasileira conferem novas atribuições aos CMEs que, desta forma, passam a desempenhar um papel fundamental como órgãos deliberativos e normativos dos sistemas municipais de ensino, com funções técnicas e políticas definidas, em que pese o fato de denunciar que, no caso do Estado da BA, os CMEs vinham se revelando incipientes, evidenciando os únicos $4 \mathrm{CMEs}$ em pleno funcionamento: Salvador, Catu, Paripiranga e Vitória da Conquista, dentre um conjunto de 30 existentes (pelo menos no período de 1988-1998), isto em um contexto marcado pela fragmentação regional, composto, à época, por 417 Municípios.

Na terceira e última região alvo das referências aqui enfocadas sobre os CMEs, a Região Sul apresenta 5 estudos concernentes a Municípios dos Estado do RS e apenas 1 relativo ao Estado de SC. A contradição entre a criação de CMEs no Estado do RS como exigência das políticas governamentais é analisada por Dall'lgna em dois estudos (DALL'IGNA, 1997; DALL'IGNA et al., 1996), destacando as dificuldades de efetiva ação desses órgãos na gestão pública e apontando a coincidência da criação dos mesmos com as políticas de municipalização do ensino. A autora sinaliza, também, o questionamento sobre as reais possibilidades dos CMEs se tornarem instrumento de participação da sociedade na gestão das políticas públicas. Para Fleck (1999), que estudou o CME do Município de Feliz (RS), esses espaços constituem-se em um canal capaz de favorecer a participação da comunidade local, permitindo, com isto, uma maior interação na busca de soluções adequadas às demandas por educação, perspectiva da qual também comunga Verza

\footnotetext{
${ }^{8}$ Recentemente, cabe destacar também, na região Sudeste, o estudo realizado no Estado do Rio de Janeiro, com foco em reflexões sobre o CME do Município de São Gonçalo, no qual Assis (2004), discute a participação da universidade nas instâncias locais de gestão, compondo o colegiado dos Conselhos de Educação.
} 
(2000) que, tomando como exemplo a criação do sistema municipal de ensino do Município de ljuí (RS), chama a atenção para o papel dos CMEs e para a importância da participação efetiva dos cidadãos na construção das políticas municipais. No caso do estudo de Rosa (2001), baseado no Município de Dom Pedrito (RS), a autora busca identificar o estilo de gestão do CME desta localidade, de acordo com a percepção de seus próprios componentes, e analisa qual a influência das ações deste Conselho na administração pública local. Em Santa Catarina, Wittmann (1996) enfoca o modelo de gestão adotado por este Estado, sinalizando para o atraso nas verbas e recursos repassados pelo Governo aos Municípios e para as estratégias político-administrativas utilizadas: terceirização; privatização; desconcentração do Estado; desarticulação das categorias funcionais; e cooptação das comunidades, prefeituras, instituições de Ensino Superior, CEE e CMEs. Analisa ainda, o fenômeno da descentralização do ensino, afirmando que esse modelo de municipalização tende a descentralizar o detalhe e centralizar as políticas, cabendo ainda ao Estado as funções de avaliação e controle. Aborda, também, a tradição brasileira de competência concorrente e não solidária, que traz conseqüências como a malversação do dinheiro público e o estímulo ao clientelismo político.

\section{A produção científica sobre os $\mathrm{CACSs}^{9}$}

No contexto acima traçado, os CACSs irão, por força de lei federal, ser constituídos, em âmbito municipal, de modo a permitir a participação social local no acompanhamento e controle dos recursos públicos em termos do FUNDEF, do Programa Nacional de Alimentação Escolar (PNAE) 10 e do Programa Nacional Bolsa-Escola (atual Programa Bolsa Família) ${ }^{1}$ ', já que o repasse desses recursos pelo Governo Federal se encontra condicionado, ente outros aspectos, à comprovação da existência de seus respectivos Conselhos. No que tange aos CACSs desses dois últimos Programas Federais, cabe de antemão destacar que, na esfera do levantamento bibliográfico realizado (SOUZA; FARIA, 2005), não se identificaram trabalhos que examinassem sua situação em Municípios brasileiros, tampouco que os discutisse teórico-conceitualmente, denotando a pouca atenção que as pesquisas científicas vêm dispensando aos mesmos ${ }^{12}$.

\footnotetext{
${ }^{9}$ Algumas das considerações constantes desta seção do texto foram extraídas de nosso outro estudo (SOUZA, 2005).

${ }^{10}$ Criado em 1954, o PNAE é parte integrante de um conjunto específico de ações da União, de natureza supletiva em relação aos Estados e Municípios, geridas pelo Fundo Nacional de Desenvolvimento da Educação (FNDE), cujos recursos contemplam os alunos que constam do Censo Escolar relativo ao ano anterior ao atendimento da Educação Infantil e do Ensino Fundamental de escolas públicas, estaduais, municipais, do Distrito Federal e de escolas mantidas por entidades filantrópicas e pela União.

${ }^{11}$ Ampliando o caráter compensatório de suas políticas educacionais e sociais, o Governo Federal, em 2001, por intermédio da Lei 10.219, constituiu o Programa Nacional de Renda Mínima vinculada à Educação - "Bolsa Escola", medida voltada à transferência de renda monetária para o atendimento de famílias pobres com filhos em idade escolar matriculados no Ensino Fundamental público. Em 2003, o Governo Federal criou um único cadastro para os beneficiários de seus programas de transferência de renda mínima, alegando que viria a contribuir para a melhora da fiscalização da aplicação dos recursos a eles destinados, agora denominado Programa Bolsa-Família, que aglutinou os benefícios do Bolsa-Escola, do Bolsa-Alimentação, do Cartão Alimentação e do Auxílio Gás.

${ }^{12}$ Mais recentemente, Algebaile (2004, p. 132), a partir de sua incursão no CACS do Programa Nacional Bolsa Escola implantado no Município de São Gonçalo (RJ), aponta para "delimitações imprecisas e ambíguas" relativas ao seu funcionamento, cujas responsabilidades deveriam estar sendo dirigidas às ações fiscalizadoras sobre a administração pública, e não à mera concessão do benefício propriamente dito.
} 
No caso do FUNDEF 13 , verifica-se que o próprio dispositivo que o criou, a Lei 9.424/96 (BRASIL, 1996), estabelece, em relação à repartição dos recursos entre os entes federados, o seu acompanhamento e controle social (Artigos $4^{\circ}$ e $5^{\circ}$ ), a ser realizado por Conselhos constituídos em cada uma dessas esferas (Município, Estado, Distrito Federal e União), denominados CACSs do FUNDEF ou, coloquialmente, Conselhos do Fundão. Informa a referida lei que os CACSs deverão caracterizar-se por não possuir estrutura administrativa própria, não devendo seus membros serem remunerados e que, na esfera municipal, a representação deverá se dar, no mínimo, por quatro membros: um representante da SME ou de órgão equivalente, outro dos professores e dos diretores das escolas públicas do Ensino Fundamental, um representante dos pais de alunos, e um dos servidores das escolas públicas do Ensino Fundamental, prevendo, ainda, a representação do CME correspondente.

Na visão de Matos (2001, p. 426), a lei atribui aos CACSs função relativamente complexa, que demanda elevado preparo por parte de seus membros, o que não se tem verificado, em muitos casos, na esfera constituída pelos Municípios: "Esses conselhos são criados por meio de lei municipal e por iniciativa do prefeito. Como são nomeados, a independência dos conselhei- ros, tão necessária ao desenvolvimento das suas atribuições, fica limitada", aspecto que leva este autor a deduzir que é grande o risco desses conselheiros não virem tendo "uma atuação efetiva e isenta"1 4 nessas instâncias de participação social.

A perspectiva acima é igualmente compartilhada por Azevedo (2002), Rodriguez (2001) e Davies (2001), este último reafirmando a pouca eficácia desses Conselhos com base em relatórios da União Nacional dos Dirigentes Municipais de Educação (UNDIME). Em outro estudo, voltado essencialmente para o exame dos CACSs (DAVIES, 2003, 2004), este autor postula que os Conselhos do FUNDEF "foram e são bastante inócuos, apesar de formalmente apresentarem um potencial para o controle social sobre o estado" (DAVIES, 2003, p. 514), acrescentando a seguir que a sua composição privilegia representantes dos governos e a participação dos conselheiros que não são formalmente do governo (professores, pais de alunos, servidores) tende a ser limitada por fatores como a disponibilidade de tempo para um acompanhamento eficiente, a falta de acesso à documentação detalhada e pertinente, e a falta de capacitação ou assessoria técnica para análise da documentação contábil. ${ }^{15}$

Levando em conta as poucas pesquisas teórico-empíricas que tomam os CACSs do

\footnotetext{
${ }^{13}$ Criado pela EC 14/96, o FUNDEF consiste num fundo contábil, de âmbito estadual, reunindo $15 \%$ de alguns impostos, repartidos entre o governo estadual e os municipais de acordo com vários critérios legais (sendo até hoje seguido apenas o de número de matrículas no Ensino Fundamental regular público). Com isto, todos os governos contribuem com esses $15 \%$ para o Fundo comum, sendo que a sua distribuição se dá em função do quantitativo de matrículas registrado na esfera do Ensino Fundamental regular. A EC 14/96 considera, ainda, que pelo menos 60\% do FUNDEF sejam aplicados no pagamento dos professores em exercício no Ensino Fundamental, disposição alterada pela Lei 9.424/96, que ora fala em valorização (Artigo $2^{\circ}$ ), ora em remuneração dos profissionais do magistério (categoria mais ampla do que professores). Além disso, a EC 14/96 prevê a destinação de 15\% de outros impostos, que não fazem parte do FUNDEF, para o Ensino Fundamental, até o ano de 2006.
}

${ }^{14}$ MATOS, 2001, p. 426.

${ }^{15}$ DAVIES, 2003, p. 514. 
FUNDEF por objeto de investigação (SOUZA; FARIA, 2005), observa-se que os prognósticos acima traçados se confirmam. Do ponto de vista da composição desses Conselhos, Gouveia e Souza (2002), em pesquisa que tomou por base Municípios do Estado do Paraná, constatam a pouca representatividade do segmento de usuários dos serviços de educação, fenômeno também examinado por Natera (2001), no âmbito do Município de Saltinho (Estado de São Paulo), que privilegiou o exame da participação dos professores e, mais recentemente, por Souza Júnior (2004, p. 14) que, investigando os CACSs dos Municípios de João Pessoa, Cajazeiras, Cabedelo e Pombal, além daquele composto em âmbito estadual (Estado da Paraíba), igualmente apontou para o "caráter oficialista dos Conselhos", expressão de "uma cultura arredia à participação social" (id), marcado pelo excesso de peso do poder público local.

Enquanto isso, outros autores como Leite (2002), com base em estudo relativo ao Município de Vitória da Conquista (Estado da Bahia), identifica a precariedade de funcionamento desses CACSs; Gomes e Pascoalino (2000), enfocam os Municípios do Estado do Ceará, constatando a nítida presença de interesses de grupos governamentais em seu interior, e Borges (2000) que, pautado em estudo realizado em Municípios do Estado de São Paulo, aponta para situações nas quais o cargo de conselheiro acaba se tornando um cargo de confiança dos prefeitos, além de verificar que o grau de complexidade dos dados a serem operados pelos CACSs demanda elevada capacitação na área. Finalmente, Andrade (2002), em trabalho realizado em seis Municípios do Estado de Goiás (Aparecida de Goiânia, Ceres, Goiás, Itapuranga, Jataí e Senador Canedo), conclui que o indica- tivo da lei do FUNDEF que versa sobre a representação da sociedade civil na composição desses Conselhos, eleitos ou indicados por seus pares, não se constitui em garantia de democracia, tese contrária à perspectiva adotada por Lima (2001), cujas conclusões resultam de pesquisa relativa ao Município de Cascavel (Estado do Paraná), que, embora reconheça que os Conselhos em tela se encontram inseridos no cenário das políticas educacionais emanadas pelos órgãos governamentais centrais, entende que podem possibilitar a democratização das políticas educacionais.

\section{Considerações finais}

No cômputo geral, preponderam estudos individuais (as co-autorias são poucas), sendo igualmente reduzido o número de casos nos quais se constataram autores que tenham publicado mais do que um trabalho distinto. Praticamente $2 / 3$ do conjunto dessas referências foram publicadas na Região Sudeste, com elevadíssima concentração no Estado de São Paulo, evidenciando as já conhecidas desigualdades ente as Regiões do País, entre os Estados de uma mesma Região e, particularmente, entre os Municípios (em especial urbanos e rurais), que aqui se manifestam na produção e no acesso diferenciado ao conhecimento científico, coerentemente às condições que marcam a história do desenvolvimento ou do não desenvolvimento - econômicosocial de cada um desses territórios.

Ainda sob uma perspectiva quantitativa, é possível afirmar que os estudos sobre os CMEs preponderam sobre os estudos relativos aos CACSs, em que pese, de um modo global, a relativa insipiência de pesquisas que tomam esses Conselhos como alvo de análise. Considerando-se que o País 
possui cerca de 5.560 Municípios, haverse-ia de esperar mais estudos sobre essas instâncias municipais, quadro que se agrava quando levado em conta, o fato de que, na esfera do acompanhamento e controle social, apenas os Conselhos do FUNDEF vêm sendo objetivados, à margem de estudos que também deveriam contemplar, com rigor e profundidade, os Conselhos do PNAE e do Programa Nacional Bolsa Escola (atual Bolsa Família), inexistentes, pelo menos dentro dos marcos temporais e documentais do levantamento realizado.

Paralelamente aos resultados já descritos, identifica-se que a preocupação com a participação da sociedade civil em ambos os Conselhos se constitui numa temática recorrente entre os trabalhos analisados, nos quais sobressai o exame em torno, não apenas do grau de sua representatividade colegiada, mas, sobretudo, no que tange à qualidade dessa participação social. De forma preponderante, os estudos em tela expõem certo descrédito em relação às possibilidades de funcionamento regular desses Conselhos, assim como em relação à possibilidade de estarem contribuindo de modo efetivo para o processo de emancipação social local, tomando-os, em alguns casos, como expressão das políticas neoliberais implantadas no Brasil a longo dos anos 1990 que, entre outros aspectos, visavam a desonerar o Estado de sua obrigação com as áreas sociais, transferindo responsabilidades para a sociedade e, de modo particular, inclusive para o indivíduo, como no caso do trabalho voluntário que se realiza nas instituições escolares. É também consensual o fato de que a lei atribui a esses Conselhos função relativamente complexa, que demanda por parte de seus membros elevado preparo, tempo e acesso a documentações detalhadas sobre a matéria, e que, na realidade da maioria das localidades investigadas, a sua criação vem se dando por intermédio de nomeações realizadas pelos prefeitos, resultando no comprometimento da independência dos conselheiros e da autonomia do órgão. No caso específico dos CMEs, nota-se, ainda, a prevalência da função deliberativa em detrimento da função consultiva e, inclusive, da função fiscalizadora.

Finalmente, chama-se a atenção para a necessidade premente de desenvolvimento de pesquisas científicas na área, quer em termos de seu aprofundamento teórico-conceitual e teórico-empírico, quer no sentido do aumento do quantitativo de estudos, bem como no que remete ao emprego de processos metodológicos que permitam comparações menos imprecisas entre os seus resultados. 


\section{Referências}

ABICALIL, C. A. O regime de colaboração na promoção da educação. In: CONFERÊNCIA NACIONAL DE EDUCAÇÃO, CULTURA E DESPORTO, 1., 2001, Brasília. Anais... Brasília, DF: Câmara dos Deputados, Coordenações de Publicações, 2001.

ABREU, M. Descentralização e federalismo. Cadernos Aslegis, Brasília, DF, v. 3, n. 7, p. 30-35, jan./abr. 1999.

ALGEBAILE, E. O que o acompanhamento do Programa Bolsa-Escola federal revela sobre os rumos da escola pública no Brasil? In: SCHEINVAR, E.; ALGEBAILE, E. Conselhos participativos e escola. Rio de Janeiro: DP\&A, 2004.

ANDRADE, M. D. P. Os Conselhos do FUNDEF: a dinâmica de implementação em municípios goianos. In: REUNIÃO ANUAL DA ANPEd, 25.; GT Estado e Política Educacional no Brasil, 2002, Caxambu. Anais... Rio de Janeiro: Associação Nacional de Pós-Graduação e Pesquisa em Educação, 2002. 1 CD-ROM.

ARELARO, L. R. G. A municipalização do ensino no Estado de São Paulo: antecedentes históricos e tendências. In: OLIVEIRA, C. et al. (Org.). Municipalização do ensino no Brasil: algumas leituras. Belo Horizonte: Autêntica, 1999.

ARRETCHE, M. T. S. Políticas sociais no Brasil: descentralização em um Estado federativo. Revista Brasileira de Ciências Sociais, Rio de Janeiro, v. 14, n. 40, p.111141, jun. 1999.

ASSIS, M. P. A participação da universidade nas instâncias locais de gestão: reflexões a partir do conselho municipal de educação de São Gonçalo. In: SCHEINVAR, E.; ALGEBAILE, E. Conselhos participativos e escola. Rio de Janeiro: DP\&A, 2004.

AZEVEDO, J. M. L. Implicações da nova lógica de ação do Estado para a educação municipal. Educação \& Sociedade, Campinas, SP, v. 23, n. 80, p. 49-71, set. 2002.

BORGES, M. R. Municipalização do ensino: um desafio para a democratização do ensino fundamental? Nuances: estudos sobre educação, Presidente Prudente, SP, v. 6, n. 6, p. 54-62, out. 2000 .

BRAVO, I. Integração e participação da comunidade no processo de municipalização em Indaiatuba. In: GIUBILEI, S. (Org.). Descentralização, municipalização e políticas educativas. Campinas, SP: Alínea, 2001. 
CALDERÓN, A. I.; MARIM, V. Educação e políticas públicas: os conselhos municipais em questão. Teias: revista da Faculdade de Educação da UERJ, Rio de Janeiro, v. 3, n. 6, p. 39-47, jul./dez. 2002.

CARVAlHO, M. L. R. D. et al. Conselho Municipal de Educação: mecanismos (in)viabilizadores da gestão democrática da escola pública municipal na microrregião de Campinas. In: GIUBILEI, S. (Org.). Descentralização, municipalização e políticas educativas. Campinas, SP: Alínea, 2001.

DALL'IGNA, M. A. Democratização do Estado e conselhos com representantes da sociedade civil: por que e para que são criados os conselhos municipais de educação. Cadernos de Educação, Pelotas, RS, v. 6, n. 9, p. 145-153, jul./dez. 1997.

DALL'IGNA, M. A.; GOULARTE, G. F.; MARTINS, E. R. Conselhos municipais de educação: participação para que? In: REUNIÃO ANUAL DA ANPEd, 19.; GT Estado e Política Educacional no Brasil (Comunicação), 1996, Caxambu. Anais... São Paulo: Associação Nacional de Pós-Graduação e Pesquisa em Educação, 1996. 1 disquete 31⁄2.

DAVIES, N. Conselhos do FUNDEF: a participação impotente. Ensaio: avaliação e políticas públicas em educação, Rio de Janeiro, v. 11, n. 41, p. 505-517, out./dez. 2003.

. Conselhos do FUNDEF: participação impotente. In: SCHEINVAR, E.; ALGEBAILE, E. (Org..). Conselhos participativos e escola. Rio de Janeiro: DP\&A, 2004.

O FUNDEF e as verbas da educação. São Paulo: Xamã, 2001.

FLECK, M. L. S. Em torno do fogo do Conselho: em busca de um final "feliz". 1999. 253 f. Dissertação (Mestrado em Educação)-Universidade do Vale do Rio dos Sinos, São Leopoldo, RS, 1999.

FREITAS, D. N. T. A gestão educacional na interseção das políticas federal e municipal. Revista da Faculdade de Educação, São Paulo, v. 24, n. 2, p. 29-47, jan./jun. 1998.

GOHN, M. G. Conselhos gestores e participação sociopolítica. São Paulo: Cortez, 2001. (Coleção Questões da Nossa Época; 84).

. novo associativismo e o Terceiro Setor. Serviço Social \& Sociedade, São Paulo, ano 19, n. 58, p. 9-23, nov. 1998.

GOMES, C. A.; PASCOALINO, H. O elo (às vezes perdido) da gestão: estudos de caso sobre resultados iniciais do FUNDEF. Revista Brasileira de Política e Administração da Educação, Porto Alegre, RS, v. 16, n. 2, p. 197-211, jul./dez. 2000. 
GOUVEIA, A. B.; SOUZA, A. R. Conselhos de acompanhamento e controle social do FUNDEF em municípios do Paraná. In: REUNIÃO ANUAL DA ANPEd, 25.; GT Estado e Política Educacional no Brasil (Pôster), 2002, Caxambu. Anais... Rio de Janeiro: Associação Nacional de Pós-Graduação e Pesquisa em Educação, 2002. 1 CD-ROM.

LEITE, M. I. P. A. FUNDEF: vitórias em Conquista. Gestão em Ação, Salvador, BA, v. 5, n. 2, p. 69-89, jul./dez. 2002.

LIMA, A. B. Conselhos municipais na educação: perspectivas de democratização das políticas educacionais. 2001. 150 f. Tese (Doutorado em Educação)-Pontifícia Universidade Católica de São Paulo, São Paulo, 2001.

LIMA, A. B.; VIRIATO, E. O. As políticas de descentralização, participação e autonomia: desestatizando a educação pública. In: REUNIÃO ANUAL DA ANPEd, 23.; GT Estado e Política Educacional no Brasil, 2000, Caxambu. Anais... Rio de Janeiro: Associação Nacional de Pós-graduação e Pesquisa em Educação, 2000. 1 CD-ROM.

MATOS, A. N. S. FUNDEF: fiscalização e controle social. In: CONFERÊNCIA NACIONAL DE EDUCAÇÃO, CULTURA E DESPORTO, 1., 2001, Brasília. Anais... Brasília, DF: Câmara dos Deputados, Coordenações de Publicações, 2001.

MEIRA, N. W. R. Conselhos Municipais de Educação e a descentralização de gestão educacional na Bahia. 1998. 126 f. Dissertação (Mestrado em Educação)-Universidade Federal da Bahia, Salvador, BA, 1998.

Conselhos Municipais de Educação e a descentralização de gestão educacional na Bahia. Gestão em Rede, Curitiba, PR, n. 32, p. 17-21, out. 2001.

- Os Conselhos Municipais de Educação na Bahia: descentralização da gestão educacional? Revista da FAEEBA: educação e contemporaneidade, Salvador, BA, v. 9, n. 13, p. 121-137, jan./jun. 2000.

. Municipalização: os Conselhos Municipais de Educação. Rio de Janeiro: DP\&A, 2004.

MENEZES, R. M. Processo de gasto e descentralização na política educacional brasileira. Em Aberto, Brasília, DF, v. 18, n. 74, p. 58-71, dez. 2001.

MONTAÑO, C. Terceiro Setor e questão social: crítica ao padrão de intervenção social. 2. ed. São Paulo: Cortez, 2003.

NATERA, J. A. B. Estudo do processo de elaboração e do conteúdo dos documentos legais que viabilizaram a municipalização do ensino na cidade de Saltinho. 2001. 92 f. Dissertação (Mestrado em Educação)-Faculdade de Educação, Universidade Metodista de Piracicaba, Piracicaba, SP, 2001. 
NOGUEIRA, S. M. A. Década de 90, as diretrizes da política educacional e o ensino fundamental: uma abordagem. Ensaio: Avaliação e Políticas Públicas em Educação, Rio de Janeiro, v. 9, n. 33, p. 459-473, 2001.

A dimensão política da descentralização participativa. São Paulo em Perspectiva, São Paulo, v. 11, n. 3, p. 8-19, jun./set. 1997.

OLIVEIRA, C.; GANZELI, P. O processo de municipalização do ensino fundamental da primeira à quarta série em Piracicaba. In: GIUBILEI, S. (Org.). Descentralização, municipalização e políticas educativas. Campinas, SP: Alínea, 2001.

OLIVEIRA, C.; TEIXEIRA, L. H. Municipalização e gestão municipal. In: WITTMANN, L. C.; GRACINDO, R. V. (Coord.). O estado da arte em política e gestão da educação no Brasil: 1991 a 1997. Brasília, DF: ANPAE; Campinas, SP: Autores Associados, 2001.

ROCHA, J. C. A participação popular nos conselhos municipais de educação na Bahia. 2001. 285 f. Dissertação (Mestrado em Educação)- Universidade Federal da Bahia, Salvador, BA, 2001.

RODRIGUEZ, V. Financiamento da educação e políticas públicas: o FUNDEF e a política de descentralização. Cadernos CEDES, Campinas, SP, v. 21, n. 55, p. 42-57, nov. 2001.

ROSA, W. B. Estilo de gestão em conselhos municipais e seu impacto numa administração pública municipal: caso do Conselho Municipal de Educação de Dom Pedrito, RS, 2001. 156 f. Dissertação (Mestrado em Administração)-Universidade Federal do Rio Grande do Sul, Porto Alegre, RS, 2001.

SAVIANI, D. Sistemas de ensino e planos de educação: o âmbito dos municípios. Educação \& Sociedade, Campinas, SP, v. 20, n. 69, p. 119-136, dez. 1999.

SILVA, S. O. Estilo de administração de três municípios do Estado de São Paulo em processo de municipalização do ensino. In: GIUBILEI, S. (Org.). Descentralização, municipalização e políticas educativas. Campinas, SP: Alínea, 2001.

SOUZA, D. B. Os conselhos de acompanhamento e controle social: seu panorama em 28 municípios do Estado do Rio de Janeiro. In: REUNIÃO ANUAL DA ANPEd, 28.; GT ESTADO E POLÍTICA EDUCACIONAL NO BRASIL, 2004, Caxambu. Anais... Rio de Janeiro: Associação Nacional de Pós-graduação e Pesquisa em Educação, 2005. 1 CD-ROM.

SOUZA, D. B.; FARIA, L. C. M. Política, gestão e financiamento de sistemas municipais públicos de educação no Brasil: bibliografia analítica (1996-2002). São Paulo: Xamã; Niterói: Intertexto, 2005. 
SOUZA, D. B.; FARIA, L. C. M. Projeto de pesquisa mapa estadual das reformas educacionais pós-LDB 9.394/96: leituras, posicionamentos e ações das secretarias municipais de educação do Estado do Rio de Janeiro (2001-2004). Rio de Janeiro: UERJ, CEH, FE, NUEPE, 2002. Mimeografado.

SOUZA JÚNIOR, L. Descentralização e controle social dos recursos da educação: os conselhos de acompanhamento do FUNDEF. In: REUNIÃO ANUAL DA ANPEd, 27.; GT ESTADO E POLÍTICA EDUCACIONAL NO BRASIL, 2004, Caxambu. Anais... Rio de Janeiro: Associação Nacional de Pós-graduação e Pesquisa em Educação, 2004. 1 CD-ROM.

VASCONCELOS, M. C. C. A casa e os seus mestres: a educação no Brasil oitocentos. Rio de Janeiro: Gryphus, 2005.

VERZA, S. B. As políticas públicas de educação no município. ljuí, RS: Ed.Unijuí, 2000.

VILABOIM, A. M. D. Ainda há lugar para os conselhos estaduais. In: SILVA, E. B. A educação básica pós-LDB. São Paulo: Pioneira, 1998.

WITTMANN, L. C. Avanços na descentralização e na participação democrática na administração da educação. In: SIMPÓSIO REGIONAL DE ADMINISTRAÇÃO DA EDUCAÇÃO DO NORDESTE, 1., 1996, Fortaleza. Anais... Fortaleza, CE: Associação Nacional de Política e Administração da Educação, Seção Ceará, 1996.

WITTMANN, L. C.; GRACINDO, R. V. (Coord.). O estado da arte em política e gestão da educação no Brasil: 1991 a 1997. Brasília, DF: ANPAE; Campinas, SP: Autores Associados, 2001.

Recebido em: 08/02/2006

Aceito para publicação em: 08/03/2006 